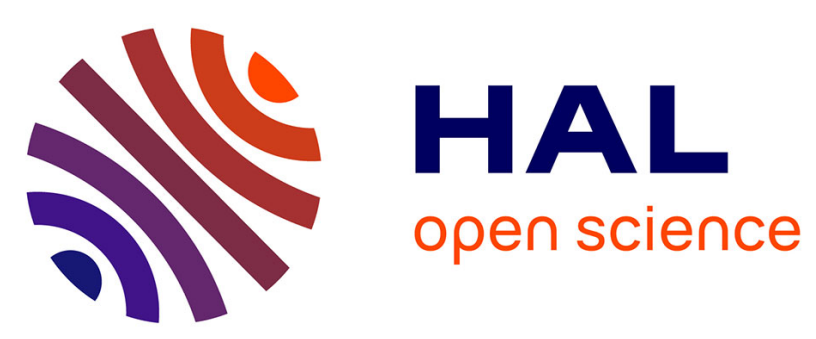

\title{
Une laïcité à géométrie variable. Les glissements idéologiques du champ politique français au début du 21ème siècle (2002-2012)
}

Kolja Lindner

\section{> To cite this version:}

Kolja Lindner. Une laïcité à géométrie variable. Les glissements idéologiques du champ politique français au début du 21ème siècle (2002-2012). Canadian Journal of Political Science / Revue canadienne de science politique, 2019. halshs-02866385

\section{HAL Id: halshs-02866385 \\ https://shs.hal.science/halshs-02866385}

Submitted on 12 Jun 2020

HAL is a multi-disciplinary open access archive for the deposit and dissemination of scientific research documents, whether they are published or not. The documents may come from teaching and research institutions in France or abroad, or from public or private research centers.
L'archive ouverte pluridisciplinaire HAL, est destinée au dépôt et à la diffusion de documents scientifiques de niveau recherche, publiés ou non, émanant des établissements d'enseignement et de recherche français ou étrangers, des laboratoires publics ou privés. 


\section{Kolja Lindner}

\section{Une laïcité à géométrie variable. Les glissements idéologiques du champ politique français au début du $21^{\text {̀̀me }}$ siècle $(2002-2012)$}

On a déjà un peu oublié les débats passionnés autour de la présidence et plus largement de l'action politique de Nicolas Sarkozy avec ses prises de positions clivantes : le discours de Dakar de juillet 2007 prétendant que «l'homme africain n'est pas assez entré dans l'Histoire », le discours de Latran de décembre 2007 soutenant que «l'instituteur ne pourra jamais remplacer le curé ou le pasteur » ou encore le discours de Grenoble de juillet 2010 menaçant de déchéance de nationalité «toute personne d'origine étrangère qui aurait volontairement porté atteinte à la vie d'un fonctionnaire de police». Loin de se réduire à des propos polémiques, ces discours véhiculent des représentations sociales, en l'occurrence des problèmes sociaux en Afrique, du rôle des cultes dans la société ou des menaces sur la communauté nationale. Et c'est en cela que la démarche de l'ancien ministre et Président français a durablement influencé la politique hexagonale ${ }^{1}$.

Je veux ici soutenir deux thèses. La première consiste à dire que la droite française s'est engagée sous la direction de Nicolas Sarkozy dans un combat pour l'hégémonie. Cet effort dispose de deux volets, l'un stratégique et l'autre motivationnel ${ }^{2}$. Alors que la dimension stratégique de l'hégémonie vise la formation d'alliances, composées d'éléments hétérogènes ou bien de forces diverses, c'est la dimension motivationnelle qui est notamment en jeu dans ce qui suit. Elle a trait à la plausibilité mentale d'un ordre dominant, donc non seulement de son acceptation passive, mais aussi de sa réception productive, de sa mise en pratique et de son développement créatif par les dominés. Dans ce sens, les politiques hégémoniques travaillent les représentations sociales dont la restructuration permet d'appuyer un ensemble idéologique qu'Antonio Gramsci appelle «équilibre de compromis »(Gramsci, 1978 : 388). Et c'est dans ce cadre que sont véhiculées les représentations sociales mentionnées.

Les Cultural Studies britanniques (Hall et coll., 1978) comme l'analyse cognitive des politiques publiques (Jobert et Muller, 1987) ont fait ressortir comment de telles représentations sociales cadrent l'action publique. Ma deuxième thèse qui sera au centre du présent article repose sur cette observation. Je soutiens que c'est sous l'influence de ce qu'on pourrait appeler une «lutte autour des chaînes de connotations» (Hall, 2012 : 160) qu'engage la droite française sous la direction de Nicolas Sarkozy, que se dynamise considérablement une transformation de la représentation de la laïcité en cours depuis la fin des années 1980. Naît ainsi ce qu’on pourrait appeler à la suite de David Koussens (2015) une "laïcité narrative» qui est différente de la «laïcité juridique» mais qui influence fortement l'action publique et la jurisprudence en matière 
des cultes. Cette représentation de la laïcité se forge particulièrement face à l'islam dont la régulation devient le souci principal de l'intervention publique en matière religieuse pendant ces dernières décennies. Cette "nouvelle laïcité » a soulevé des critiques parce qu'elle constitue un discours qui cherche à soumettre des individus à une obligation de neutralité religieuse tout en se donnant «comme inscrit dans la tradition républicaine (celle de la loi de 1905), alors même qu'il en propose une modification substantielle» (Vauchez et Valentin, $2014: 40$ ).

Pour comprendre ce changement de sens, il est indispensable de revenir, dans un premier temps, sur la laïcité historique, à savoir sur la genèse du dispositif juridique découlant du principe de laïcité. Je montrerai que ce dispositif présente un «libéralisme ambigu » et culturellement biaisé. Après avoir examiné le rapport particulier que la laïcité «à la française » entretient depuis son émergence avec l'islam, je reviendrai, dans un second temps, sur la récente évolution de la laïcité en montrant comment celle-ci s'éloigne concrètement des éléments libéraux de la formule initiale tout en accentuant ses ambivalences et biais culturels. La conjoncture politique récente dont je propose l'analyse, l'action politique de Nicolas Sarkozy entre 2002 et 2012, se caractérise par trois logiques différentes dont le développement chronologique illustre le cheminement des ambitions hégémoniques de la droite pendant cette période. Cette chronologie approximative qui porte des traits d'idéaux types structure ma réflexion dans la deuxième partie du présent article : premièrement, l'appropriation de la laïcité par le parti de droite divisé au sujet du rapport que l'État devrait entretenir avec l'islam («nouvelle laïcité ») ; deuxièmement, la « nationalisation » de la laïcité et la prise de distance par rapport au culte musulman quand le pacte qu'une partie de la droite lui propose s'avère inefficace («laïcité positive»); troisièmement, la radicalisation de la laïcité qui en fait une idéologie ouvertement antimusulmane (« laïcité falsifiée »).

\section{Libéralisme laïque et tentation autoritaire}

\section{Genèse des normes et du dispositif lä̈que}

Les fondements juridiques de la laïcité en France ont été forgés sous la III ${ }^{\text {ème }}$ République, au cours d'une séquence politique allant de 1879 à $1907^{3}$. Ce régime met alors fin au gallicanisme, c'est-à-dire à la forte intrication entre politique et religion caractérisant la France depuis la fin du $13^{\text {ème }}$ siècle. Le "moment laïque» se décompose en trois actes (les lois sur l'école, sur les associations puis sur la séparation des Églises et de l'État), le Concordat en Alsace-Moselle présentant dès le début un autre régime de régulation du religieux en métropole. De nombreux travaux disponibles sur ce moment fondateur permettent de soutenir mon interprétation et en particulier de clarifier le rapport entre les différents principes laïques dont j'analyserai dans une deuxième partie la réarticulation récente face à l’islam. 
Au début de la III ${ }^{\text {ème }}$ République, le débat politique porte principalement sur l'école, institution à laquelle on impute communément le désastre de la guerre. Mona Ozouf soutient ainsi qu'« au lendemain de la défaite [...] naît l'idée d'un choix nécessaire à opérer entre l'école et l'Église. Pour les uns, il faut accroître l'autorité de l'Église sur l'école. Pour les autres, il faut hâter leur divorce» (1982: 27). Tandis que les Républicains tentent d'«assurer le pouvoir par l'organisation de l'enseignement» (ibid. : 55), les conservateurs réclament eux la «liberté de l'enseignement ».

Cette configuration présente un paradoxe majeur. C'est en se saisissant des libertés civiques garanties par le nouveau et contesté régime républicain (liberté de la presse, de conscience, de rassemblement, et ainsi de suite) que le catholicisme peut connaittre un substantiel renouveau, marqué notamment par le développement d'écoles privées «libres », d'une presse moderne et active, de nombreux organismes de charité, d'une pastorale renouvelée, et ainsi de suite (Encrevé et coll., 1995). Entre 1879 et 1889, neuf lois portent sur le domaine de l'école « toutes portées par l'intention de placer l'éducation sous tutelle de l'État, et à l'abri de l'influence de l'Église» (Portier, 2016 : 104) : la loi du 9 août sur l'établissement des écoles normales primaires ; la loi du 27 février 1880 relative au Conseil supérieur de l'instruction publique et aux conseils académiques; la loi du 18 mars 1880 relative à la liberté de l'enseignement supérieur ; la loi du 21 décembre 1880 sur l'enseignement secondaire des jeunes filles ; la loi du 16 juin 1881 établissant la gratuité absolue de l'enseignement primaire dans les écoles publiques ; la loi du 16 juin 1881 relative aux titres de capacité exigés pour l'enseignement primaire; la loi du 28 mars 1882 sur l'enseignement primaire obligatoire; la loi du 30 octobre 1886 sur l'organisation de l'enseignement primaire et enfin la loi du 19 juillet 1889 transformant les instituteurs en fonctionnaires d’État. Le dispositif qui exprime au mieux le libéralisme de ces textes, c'est-à-dire la volonté publique de ne pas interférer avec les pratiques religieuses elles-mêmes tout en réduisant l'influence des institutions ecclésiastiques, est sans doute celui de la loi du 28 mars 1882 qui prévoit de libérer un après-midi dans les écoles publiques pour l'enseignement éventuel du catéchisme.

En réponse à «l'engagement massif de la presse et des élites catholiques dans le camp antidreyfusard» (Pelletier, 2007 : 315), la République procède au deuxième acte des lois laïques. Celui-ci vise notamment les congrégations qui disposent alors d'une influence idéologique considérable sur les écoles privées. La loi du $1^{\text {er }}$ juillet 1901 crée un statut d'association à but non lucratif, donnant ainsi à l'État la possibilité de dissoudre les congrégations. On doit retenir avec Pierre Rosanvallon que «la question des congrégations a largement dépassé [...] celle des rapports entre l'Église et l'État. C'est la définition même de ce dernier dans son lien à la société qui a en fait constitué le véritable enjeu des débats passionnés sur le droit d'association. Il en est résulté 
une singulière conception de la société civile en France. Elle n'a pas été pensée dans sa différence à l'État mais dans sa rupture avec le monde religieux »(Rosanvallon, 2004 : 326). L'idée d'une neutralité religieuse de la sphère publique au sens large, c'est-à-dire de la société civile et non de l'État, qui représente un trait central de la laïcité reformulée au début du $21^{\text {̀̀me }}$ siècle, trouve ici sa source historique ${ }^{4}$.

À l'époque, cette conception intransigeante de la laïcité fait par ailleurs l'objet de fortes critiques, revendiquant notamment déjà le respect des droits de l'Homme. Ainsi, René Goblet, principal responsable de la loi de 1886, soutient que la nouvelle règlementation constituerait « une atteinte incontestable» aux «droits de toute une catégorie de citoyens", à savoir les congréganistes et, au-delà, aux «droits des pères de famille » (cité dans Baubérot, 2004 : 79) dans l'éducation de leur enfants. Le camp des Républicains est désormais traversé par un profond clivage. D’un côté, les défenseurs d’une laïcité libérale cherchent à garantir les libertés individuelles dans un cadre étatique neutre et de l'autre, les avocats d'une «laïcité intégrale » (qu'on appellera aussi « laïcards ») mettent en avant les prérogatives de l’État et son devoir moral de protéger les citoyens de la religion, voire de les émanciper d'elle. L'arrangement finalement établi porte les traits des deux conceptions : la République « défend de concert, sans toujours pouvoir les articuler, la liberté du sujet et la raison de l'État» (Portier, 2016 : 113).

Les lois de séparation des Églises et de l'État de 1905 et 1907 constituent le troisième acte de la mise en place du dispositif laïque de la III ${ }^{\text {ème }}$ République. Face aux tentatives des Radicaux d'accroitre le contrôle étatique de l'Église, les laïques libéraux s’imposent et soumettent la «Loi concernant la Séparation des Églises et de l'État», promulguée le 9 décembre $1905^{5}$. Les sept articles centraux de cette dernière suppriment le Concordat, c'est-à-dire le règlement conclu entre Napoléon Bonaparte et le Pape en 1801 établissant un lien étroit entre Église et État. Est ainsi créé un nouveau régime du traitement étatique des institutions et du personnel ecclésiastiques ainsi que du culte.

Selon l'article premier, « la République assure la liberté de conscience » et « garantit le libre exercice des cultes » qui peut être limité seulement par la nécessité de garantir «l'ordre public ». L'article deux énonce que «la République ne reconnait, ne salarie ni ne subventionne aucun culte ». Une exception, soulignant à nouveau l'importance qu'attribue la majorité des Républicains aux droits civiques, est aménagée par l'obligation pour les institutions publiques d'assurer l'accès aux cultes. Les pouvoirs publics financent ainsi des aumôneries dans les écoles, les hôpitaux, les prisons ou à l'armée pour garantir la liberté de conscience. L'article quatre prévoit le transfert et la location des édifices religieux aux représentants des «associations qui, en se conformant aux règles d'organisation générale du culte dont elles se proposent d'assurer l'exercice, se seront légalement formées ». Enfin, les articles 18 à 20 obligent les associations cultuelles à se soumettre 
à la loi du $1^{\text {er }}$ juillet 1901, à « avoir exclusivement pour objet l'exercice d'un culte » (art. 19), à disposer d'une certaine représentativité numérique ainsi que d'une administration propre ou d'une direction centrale, à présenter un règlement interne permettant une affiliation réversible et à gérer leurs finances de manière transparente.

Ces règlements qui imposent à l'Église un corset libéral et nationalisent ses biens, provoquent une résistance farouche. Le refus du Pape de créer des associations cultuelles mène à une autre loi adoptée le 2 janvier 1907. Il s'agit à nouveau d'une réponse libérale au conflit dans la mesure où, «à défaut d'associations cultuelles » (art. 5), les pouvoirs publics mettent à disposition des édifices cultuels aux fidèles et à leurs ministres du culte pour la pratique de leur religion. Il s'agit là d'un règlement qui «profite largement aux anciens cultes reconnus, c'est-à-dire aux grandes traditions religieuses françaises » (Koussens, 2015 : 88), renforcé par le privilège accordé à l’Église catholique avec l'accord de 1923-1924 instaurant les « associations diocésaines ».

Ce dispositif juridique ne s'applique pas aux trois départements de l'est de la France (BasRhin, Haut-Rhin et Moselle) qui se trouvent sous autorité allemande depuis 1871. Le Concordat y reste en vigueur et les cultes reconnus (catholique, luthérien, réformé et israélite) continuent à disposer d'une grande influence dans les institutions publiques: nombreux fonctionnaires religieux sont nommés et financés par les autorités publiques, les lieux de culte reçoivent des subventions de l'État et les institutions publiques d'enseignement secondaire et supérieur offrent des enseignements et formations religieuses.

La persistance du Concordat dans l'Alsace-Moselle après sa réintégration au sein de la République française à l'issue de la Première Guerre mondiale n'est cependant pas la seule exception à la laïcité. Il y en a en effet quatre autres dans différents départements et collectivités d'outre-mer qui subsistent encore aujourd'hui. Bien que le Conseil constitutionnel ait décidé de constitutionnaliser la reconnaissance des cultes et le versement de traitement aux pasteurs, rabbins et prêtres en Alsace-Moselle, ainsi que le droit des cultes applicable outre-mer le 21 février 2012, l'existence de ces structures pose de sérieuses questions quant à l'exigence jacobine et égalitariste d'une République «une et indivisible». Historiquement, l'exemple le plus flagrant de ces dérogations est cependant représenté par l'Algérie sous occupation française, dont je vais traiter plus loin.

\section{Un « libéralisme ambigu » et culturellement biaisé}

On peut soutenir avec Jean-Pierre Machelon, que la III ${ }^{\text {ème }}$ République est caractérisée par un «libéralisme ambigu» (1976: 449). Ainsi, les libertés civiques instaurées permettent, et c'est presqu'une ironie de l'histoire, un renouveau catholique. Concernant la loi de 1905, il a été retenu qu'elle marquait «un infléchissement libéral» (Portier, 2016: 143), voire qu'elle était 
«politiquement libérale et religieusement accommodante» (Baubérot, 2012 : 184). En effet, le législateur souhaite «non pas déclarer la guerre à l’Église catholique, mais redéfinir les liens entre l'Église et l'État républicain », comme le précise Philippe Icard (2005 : 571). Contrairement à une idée courante, le dispositif laïque ne suspend pas tout rapport entre l’État et les cultes. «En dépit de son titre ambitieux », la loi de 1905 a « un objet plus modeste : elle privatise le service public des cultes et supprime son organisation publique par l'État; elle libère et libéralise leur exercice public, antérieurement limité aux quatre cultes reconnus; elle maintient et garantit le caractère public de cet exercice dans des édifices cultuels qui relèvent massivement du domaine public », soutient pour sa part Émile Poulat (2010 : 27). La République laisse la liberté aux citoyens de s'orienter spirituellement et intellectuellement. Elle reconnait «le fait religieux en tant qu’il est lié aux libertés publiques et aux droits de l'homme, sans avoir donc à se prononcer sur sa positivité, sa vérité ou sa divinité » (ibid. : 167). Selon la loi de 1905, l'appartenance collective, qu'elle soit religieuse ou pas, «constitue une dimension de la liberté individuelle » (Baubérot, 2006 : 159). Enfin, les communautés religieuses se voient attribuer le droit de s'organiser selon leurs propres règles, pourvu que celles-ci ne rentrent pas en conflit avec la loi.

Ce libéralisme est d'autant plus remarquable que le dispositif laïque est contemporain de l'affaire Dreyfus, qui exacerbe l'intense lutte de pouvoir entre la République et l'Église catholique. Toutefois, la tentation autoritaire « laïcarde » voire anticléricale reste bien présente dans le camp républicain, même si elle n'est pas majoritaire. Mon propos n'est pas de nier les tensions entre les différentes conceptions de la laïcité qui ont nourri le dispositif läque. Au contraire, je soutiens qu’il est le produit d'une synthèse entre des éléments libéraux et autoritaires.

Il est important de noter que le libéralisme des normes laïques ne s'exprime pas seulement dans leur contenu mais aussi dans leur articulation, plus précisément, dans leur hiérarchisation. Outre la liberté de conscience, la laïcité se caractérise par les principes d'égalité de traitement des différents cultes et de neutralité confessionnelle de l'État. Le premier des deux, exprimé notamment par l'emploi du pluriel dans le titre de la loi de 1905 («Séparation des Églises et de l’État»), rend possible un traitement public non-discriminant de la diversité religieuse «à condition de sa neutralisation politique relative»(Balibar, 2012: 623). Le troisième principe laïque, la neutralité confessionnelle de l'État, est enfin contenu dans l'article deux de la loi de 1905, qui instaure la non-reconnaissance des cultes. Neutralité veut dire ici que l'État ne défend pas une conception spécifique de la vie bonne qu'il imposerait à ses sujets. En même temps, il n'est pas complètement séparé de la religion, mais se trouve dans une distance de principe par rapport à elle. Ses fins et institutions sont neutres et il dispose seulement d'un ensemble de valeurs nécessaires à l'épanouissement et à la cohabitation de différents cultes et des conceptions de la vie bonne qui les sous-tendent. 
Sur le plan juridique (la jurisprudence du Conseil constitutionnel ainsi que du Conseil d'État jusqu'en 2002, le début de ma période d'enquête, le confirme), la liberté de conscience se trouve en tête de la hiérarchie des normes laïques : elle est solennellement énoncée dans l'article premier de la loi de 1905 et appuyée par des arrangements tacites (comme la mise à disposition des édifices), des accommodements fonctionnels (notamment dans l'organisation du temps scolaire) et des dérogations institutionnelles (rémunération des aumôniers par l'État). Ces dernières ne portent pas atteinte à la neutralité de l'État parce qu'« elles n'ont pas pour objectif de promouvoir l'expression d'une religion dans la sphère publique mais se justifient par l'obligation de favoriser l'exercice de la liberté de conscience et de religion»(Koussens, 2015: 118). Cependant, les principes laïques ne sont pas parfaitement harmonisés. L'État doit alors " procéder à des arbitrages dans la détermination du poids qu'il importe de leur accorder dans le traitement d'un fait social. Et c'est ici que la neutralité devient un indicateur des aménagements de la laïcité dans une société» (ibid.: 54). Ses déploiements révèlent certains fondements philosophiques, culturels et politiques et ne peuvent donc pas être parfaitement neutres.

Le biais culturel de l'arrangement de la laïcité française s'exprime par exemple dans le privilège structurel du culte catholique ${ }^{6}$. Un élément de ce biais culturel est particulièrement délicat parce qu'il crée le risque d'une atteinte au principe même de l'égalité de traitement. Il s'agit du dispositif des aumôniers qui sont nommés par la hiérarchie ecclésiastique (dans le cas des cultes chrétiens) ou par le Consistoire central israélite de France, créé par Napoléon en 1808 à l'instar des autres cultes reconnus pour administrer le culte juif. Dans son fonctionnement, la laïcité présuppose donc une certaine structuration et représentation de la communauté des fidèles qui est loin d'être universelle. L'atteinte à l'égalité qui en résulte a particulièrement touché l'islam : jusqu'en 2003, il n'y avait pas de représentation officielle du culte musulman en France.

\section{Laïcité et islam}

Indépendamment de tout biais culturel, la laïcité française entretient historiquement un rapport particulier à l'islam, culte auquel elle a notamment été confrontée dans le cadre colonial. Ce rapport est dérogatoire, la loi de 1905 prévoyant un régime d'exception. Son article 43 énonce ainsi que « des règlements d'administration publique détermineront les conditions dans lesquelles la présente loi sera applicable en Algérie et aux colonies »- l'Algérie, déclarée partie intégrante du territoire national et divisée en trois départements en 1848, disposant d'un statut particulier.

L'enjeu particulier de ces règlements réside dans le maintien d'une intrication étroite entre l’État et les différents cultes appuyant la domination coloniale. Ainsi, les missions chrétiennes présentent un renfort à la présence française et sont subventionnées et contrôlées par les autorités coloniales. L’islam algérien, après avoir été réprimé dans la première phase de la 
colonisation, est organisé par l'État à partir de 1851. Les subventions publiques et la formation des imams dans des écoles créées par l'administration française sont censées assurer la loyauté du culte musulman. En 1866, l'Algérie est intégrée dans le régime concordataire et érigée en $18^{\text {ème }}$ province ecclésiastique. L’islam y devient le quatrième culte reconnu en 1881.

L’introduction du dispositif laïque en Algérie aurait ainsi mis fin à cette fonctionnalisation des cultes. Pour l'éviter, le décret d'application du 27 septembre 1907 maintient la possibilité de subventions étatiques du personnel religieux que le Gouverneur peut décider dans l'«intérêt public et national». Ces dérogations ne valent pas seulement pour l'islam ${ }^{7}$. Les subventions publiques de l'Église catholique sont également maintenues afin de détourner l'influence du Vatican, risque réel au vu du nombre important de colons italiens. Même après 1905, l'ensemble des actions publiques en matière religieuse continue donc à maintenir un véritable «gallicanisme colonial» (Frégosi, $2008: 206)$.

Au delà de ces dérogations, le rapport historique entre République et islam a forgé des représentations sociales de ce dernier. La première consiste dans l'idée que les musulmans sont d'eux-mêmes incapables de concevoir la laïcité et qu'ils doivent par conséquent être éduqués pour pouvoir remplir ses exigences de liberté, d'égalité et de neutralité. Ainsi, la capacité laïque des musulmans a été au cœur du débat autour des conceptions d'assimilation ou d'association de l'Algérie qui a lieu en métropole à la fin du $19^{\text {ème }}$ et au début du $20^{\text {ème }}$ siècle (Luizard, 2006b ; Bozzo, 2006 : 211-213). D’un point de vue du principe de séparation, la «mission civilisatrice» que prétend réaliser le pouvoir colonial français est particulièrement incohérente parce qu'elle est au moins partiellement portée par les écoles missionnaires, ces institutions relevant pour une bonne partie des congrégations qui sont alors fortement réprimées en métropole. La loi de 1904 proscrivant leur enseignement ne change ainsi rien à l'organisation scolaire en Algérie. Au contraire, deux décrets promulgués le 16 janvier et le 6 décembre 1939 par le Ministre des Colonies, Georges Mandel, créent un statut juridique pour les missions, encore en vigueur aujourd'hui dans la plupart des collectivités d'outre-mer.

La deuxième représentation sociale de l'islam influente jusqu'à aujourd'hui tient au racisme des autorités coloniales: à rebours des normes laïques, notamment du principe de l'égalité de traitement, les musulmans sont ouvertement discriminés ${ }^{8}$. En fait, le droit colonial français ne cesse de créer des hiérarchies essentialisées. À partir de 1865, tous les habitants d'Algérie sont considérés comme des «sujets de la France » à distinguer des «citoyens français ». Cette règle ne s'appliquera pas longtemps aux colons chrétiens: dès 1889, tout Européen occidental relevant de ce culte et s'installant en Algérie est naturalisé français sans devoir en faire la demande. En octobre 1870, un décret du Ministre de la Justice, Adolphe Crémieux, accorde les pleins droits civiques aux Juifs d'Algérie. Selon Pierre Rosanvallon, il s'agit là d'une 
règlementation portée par l'idée d'«une différence de "capacité laïque" entre l'islam et le judaïsme» (1992: 429). Suspendu au temps de l'administration vichyste (1940-1943), le décret restera en vigueur jusqu'à la libération de l'Algérie. En revanche, les musulmans sont soumis, à partir de juin 1881, à une juridiction d'exception qui supprime notamment la séparation des pouvoirs judiciaires et exécutifs, et codifie tout un ensemble de nouveaux délits et sanctions (Merle, 2002). Ce Code de l'indigénat n'est abrogé qu'en 1944. Le racisme qui anime le pouvoir colonial est encore plus tangible dans la mise en œuvre des naturalisations des indigènes musulmans à partir de 1865. Celle-ci présuppose une conversion et va de pair avec des contrôles de la situation familiale et des mœurs. Cette politique est soutenue par la conception d'une «population d'exception» (Constantini, 2008: 65), incapable de s'intégrer complètement. L'exemple des musulmans algériens convertis au catholicisme l'illustre bien. Il n'y pas de naturalisation automatique pour eux, ce que la cour d'appel d'Alger justifie de la manière suivante en 1903 : le terme musulman «n'a pas un sens purement confessionnel, mais [...] désigne au contraire l'ensemble des individus d'origine musulmane [...] sans qu'il y ait lieu de distinguer s'ils appartiennent ou non au culte mahométan » (cité dans Weil, 2008 : 118).

Bien que la situation soit différente en métropole, l'islam n'y est pas non plus intégré dans le dispositif laïque. Les premières implantations significatives de populations musulmanes remontent à la Première Guerre mondiale avec la mobilisation de nombreux soldats coloniaux. À l'encontre des principes de la loi de 1905, le Ministère des Affaires étrangères finance alors une mosquée dans un hôpital militaire en 1915 tandis que l'Assemblée nationale et la mairie de Paris subventionnent la construction de la Grande Mosquée de Paris (GMP) en 1920. Le bâtiment est érigé en «temple du culte musulman de France» pour compenser le lourd tribut de sang des soldats musulmans (Davidson, 2012 : 36-61). Avec les ambassades du Maroc et de la Tunisie qui, après l'indépendance des deux pays, sont «souvent sollicité[e]s par les autorités françaises pour contrôler leur ressortissants » (Gresh, 2004 : 145), la GMP, étroitement contrôlée par les autorités en Algérie, assure désormais la représentation officielle du culte musulman en France.

Cette situation change à partir de 1979, lorsque la révolution islamique en Iran favorise un glissement sécuritaire de l'action publique. Les réflexions sur la création d'un organe de représentation du culte musulman débutent à ce moment-là. Elles sont dynamisées par la reconnaissance du droit d'association des étrangers par le gouvernement socialiste en 1983 menant à la création d'associations revendiquant une représentation de l'islam de France, notamment l'Union des organisations islamiques de France (UOIF) et la Fédération nationale des musulmans de France (FNMF). Tout au long des années 1980 et 1990, la rivalité entre ces différentes sensibilités islamiques empêche la création d'une instance unique représentant l'ensemble de l'islam. 


\section{Les transformations récentes de la laïcité}

\section{La « nouvelle laïcité »}

Le renouveau du débat sur la laïcité au début du $21^{\text {ème }}$ siècle tient ainsi largement à la résurgence de l'attention des pouvoirs publics pour la représentation du culte musulman. Deux évènements, et surtout les évolutions des représentations sociales qui les accompagnent, en sont le détonateur. Le premier consiste dans les attaques terroristes du 11 septembre 2001 qui renforcent une conception essentialisante de l'islam, supposant que l'ensemble des actions sociales des musulmans serait déterminé par leur appartenance religieuse (Mamdani, 2004 : 1762 ; pour le discours médiatique français à propos de l'islam après les attentats de 2001 : Deltombe, 2005 : 267-292). Par conséquent, la gestion publique de l'islam apparait comme un moyen de répondre à la menace de nouveaux attentats. S'ajoute l'attention publique pour les financements étrangers des lieux de culte musulmans, perçus désormais comme une "porte d'entrée » privilégiée de l'islamisme. Ces flux monétaires comblent l'absence d'un financement public des mosquées en vertu de la loi de 1905, et compensent le manque de ressources de la communauté musulmane de France qui, dans sa très grande majorité, est d'origine sociale modeste car issue des classes populaires migrantes.

Le deuxième évènement qui pèsera politiquement dans ces années-là, c'est l'accession du candidat d'extrême droite au deuxième tour de l'élection présidentielle de 2002, suite à une campagne électorale durant laquelle l'enjeu de la sécurité intérieure a été omniprésent (à propos de la surreprésentation médiatique de la délinquance dans la campagne présidentielle de 2002 : Macé, 2002). Au centre de cette préoccupation médiatique se trouve une figure fortement genrée, racisée et assignée à l’islam : le « jeune de banlieue », dont la délinquance supposée est présentée comme un danger majeur pour les valeurs républicaines et la cohésion nationale (GuénifSouilamas et Macé, 2006 ; Deltombe, 2005 : 293-315). Cette population et les inconduites qu'on lui prête donnent alors lieu à une véritable "panique morale », à l'instar de celle qu'a connu la Grande-Bretagne à la veille de l'élection de Margaret Thatcher en 1979 (Hall et coll., 1978). Le résultat du premier tour de l'élection présidentielle de 2002 illustre bien un glissement politique appuyé par la soudaine apparition de cette représentation sociale : outre l'accession au second tour du candidat du Front national (FN), l'abstention atteint un niveau record (28,4\%), tandis qu'aucun candidat des partis établis ne dépasse la barrière des $20 \%$ et que tous ceux représentant l'extrême gauche atteignent les 10\% (Perrineau et Ysmal, 2003). L'insécurité est devenue «un critère de jugement des politiques » (Artufel et Duroux, 2006 : 203) même pour les électeurs de gauche. 
C'est dans ce climat politique que Nicolas Sarkozy arrive place Beauvau, en mai 2002. Avec un «intérêt quasi passionnel» (Terrel, 2008 : 88), le nouveau Ministre de l'Intérieur s'empare presque aussitôt du dossier de la représentation du culte musulman. Exerçant une forte pression sur la GMP, l'UOIF et la FNMF avec l'appui des ambassades nord-africaines, Nicolas Sarkozy réussit à imposer un compromis : la création du Conseil français du culte musulman (CFCM) dont la direction est assurée par le directeur de la GMP, Dalil Boubakeur. Le système de représentation instauré prend notamment en compte la taille des mosquées et des salles de prière dont disposent les différentes organisations musulmanes.

Reposant sur une certaine essentialisation de la population originaire de pays majoritairement musulmans ${ }^{9}$, la démarche du Ministre de l'Intérieur, se veut une réponse à la menace du terrorisme islamiste : «l'État ne peut pas [...] se désintéresser du développement d'un islam clandestin, qui lui, précisément, cherche à ébranler nos principes de gouvernement et nos valeurs fondamentales. Quant à ceux qui refusent de voir que la République n’a rien à perdre au rayonnement de religions structurées et pacifiées, ils font à mon sens une erreur de perception de l'importance de la question religieuse dans la conscience humaine et l'équilibre social. Ce qui serait contraire à la laïcité, ce serait de faire pour les fidèles d'une religion quelque chose que l'on refusait aux autres religions. Mais aider l'islam à s'organiser, dès lors qu'il en a besoin, ne retire rien aux autres religions, ni aux non-croyants, et sert les intérêts de la République. Il n'y a pas atteinte au principe de la laïcité » (Sarkozy, 2004 : 65 passim). En même temps, avec la création du CFCM (et la reconnaissance publique de l'UOIF, jusqu'à présent évitée par les pouvoirs publics, en particulier par les gouvernements de droite historiquement proches de la GMP), "Nicolas Sarkozy prône, en partie, une "solution religieuse" aux problèmes de délinquance et d'insécurité dans les quartiers populaires»(Geisser et Zemouri, 2007: 110) ${ }^{10}$. Cette politique poursuit une ambition hégémonique car elle cherche à former une nouvelle alliance politique avec des acteurs islamiques et s'appuie pour cela sur une certaine représentation de l'état du rapport entre l'État et les cultes : «La situation actuelle est l'héritage du désintérêt, de la nonreprésentation du culte musulman, de l'indifférence à l'endroit des conditions dégradées dans lesquelles certains de nos concitoyens vivaient leur foi. D'ailleurs, on ne s'est pas intéressé non plus aux jeunes, aux banlieues, à la sécurité, aux questions de réussite et d'intégration. J'ai proposé un changement complet de stratégie. Il fallait agir en créant le CFCM et nous devons faire de toutes ces questions des sujets d'actions prioritaires » (Sarkozy, $2004: 85$ ).

Quelle est la conception de la laïcité qui sous-tend cette action? La politique du Ministre de l'Intérieur en matière religieuse témoigne en réalité pleinement de l'ambivalence que j'ai fait ressortir plus haut. D’une part, il affiche un vrai souci d'égalité : le CFCM devrait garantir l'intégration du culte musulman dans le dispositif laïque, remédiant ainsi à son biais culturel. Par 
conséquent, le nouvel organe est censé nommer les aumôniers pour les institutions publiques telles que prisons, hôpitaux, et ainsi de suite. De plus, l'État respecte la liberté d'organisation du culte, inscrite dans l'article 4 de la loi de 1905. Il « ne s'est pas limité à la prise en compte gallicane d'un islam dit "modéré". L'ensemble des courants représentatifs de la communauté musulmane [...] a participé » (Baubérot, 2004 : 255) à la création du CFCM. Avec l'UOIF, Nicolas Sarkozy a même pris soin d'impliquer un acteur associatif vis-à-vis duquel le monde politique est d'ordinaire, pour le moins, très réticent. Le processus aboutissant à l'établissement du nouvel organe de représentation s'inscrit d'autre part dans la tradition de déroger à la laïcité face à l'islam. Sadek Sellam soutient ainsi que «le problème de la séparation de l'islam et des États reste entier, un siècle après le vote de la loi de 1905 »(2006 : 318), alors que certaines ambassades ont été étroitement associées aux négociations. Puis, la demande faite aux membres du CFCM de reconnaittre explicitement les lois de la République «dans une sorte de "moment concordataire", - car le mot même de "reconnaissance" a été prononcé - temporaire et instable, fixé dans une procédure de double reconnaissance politique» (Zeghal, 2005 : 112), semble également déroger aux principes laïques originels. On peut donc retenir que la nouvelle politique publique envers le culte musulman met en avant dans son appréhension de la laïcité les valeurs de liberté et d'égalité au détriment des principes de non-reconnaissance et de séparation.

La nouvelle proximité des pouvoirs publics avec les organisations musulmanes et la réinterprétation du rapport entre République et islam qui la sous-tend, ou pour le dire autrement le volet stratégique et motivationnel de l'ambition hégémonique de Nicolas Sarkozy en matière de laïcité, provoquent de fortes résistances à droite comme à gauche. La reconfiguration du débat sur la laïcité qui s'ensuit doit beaucoup à cette convergence interpartisane. L'opposition la plus notable vient des adversaires de Nicolas Sarkozy au sein du parti majoritaire. Le rapport «Pour une nouvelle laïcité », rédigé par le député chiraquien François Baroin et publié en mai 2003, en présente la version la plus synthétique. Le parlementaire y soutient qu'on assisterait à «un déplacement des enjeux liés à la laïcité, de la sphère religieuse à la sphère culturelle et identitaire » (Baroin, 2003). La laïcité ferait désormais partie de «l'identité nationale » (ibid.), que l'État devrait défendre face à la pluralisation religieuse. François Baroin perçoit trois défis majeurs : un anachronisme de la laïcité dont les grands principes « ne permettent pas toujours de répondre aux questions posées aujourd'hui, en particulier par l'islam » (ibid.) ; un devoir pour l'État de garantir la liberté de conscience face aux politiques d'identité musulmanes qui viseraient à imposer des codes de conduite aux non-musulmans; et enfin, la nécessité d'une politique laïque «qui fixe des limites déterminées par les valeurs démocratiques et humanistes, au premier rang desquelles la dignité de la femme et la non-discrimination» (ibid.) - si nécessaire par « une modification du droit applicable en matière de port des signes d'appartenance religieux » (ibid.) ${ }^{11}$. Face à la 
contestation de la laïcité par «certaines populations immigrées [...] qui, issues d'une culture non laïque et non démocratique, ne perçoivent pas le sens de ce principe » (ibid.), les pouvoirs publics devraient affirmer la souveraineté temporelle. Selon François Baroin, «l'enjeu dans certains pays musulmans et dans certaines banlieues françaises» (ibid.) serait donc le même : «il s'agit de déterminer la loi applicable» (ibid.). Et cette mission politique ferait qu'«à un certain point, la laïcité et les droits de l'homme sont contradictoires » (ibid.).

Cette reconceptualisation de la laïcité, sa mise en «narration», qui se veut une « réponse au choc du 21 avril $2002 »$ (ibid.) va fournir l'essentiel des éléments justificatifs pour l'interdiction des signes religieux dits ostentatoires à l'école publique, votée en mars 2004. Dans les deux commissions qui préparent cette prohibition (l'une parlementaire, l'autre «experte »), la « nouvelle laïcité » s'impose comme une «idéologie de groupe » (Baubérot, 2008: 237) ${ }^{12}$. Quatre thèmes récurrents dans les deux rapports issus des travaux en témoignent:

- La laïcité est conçue comme une affaire touchant «à l'identité nationale, à la cohésion du corps social» (Stasi, 2003 : 36). Elle ne serait "pas uniquement un mode de régulation des relations entre l'État et ses institutions d'une part et les religions d'autre part» (Debré, 2003a : 64), mais un "projet, à la fois politique et social, d'intégration des individus dans une communauté nationale une et indivisible » (ibid. : 42). La laïcité se voit ainsi conférée le rôle de créer une « communauté d'affections » (Stasi, 2003 : 18).

- Les membres des deux commissions partagent l'idée d'un défi particulier et nouveau résultant des politiques d'identité musulmanes : «le débat sur la laïcité ne se pose plus dans les mêmes termes qu'au début du siècle. Alors qu'en 1905, le juge devait assurer la garantie de la liberté de conscience et de sa libre expression face à des comportements anticléricaux, il est aujourd'hui confronté à des comportements identitaires de types divers qui remettent en cause le modèle républicain d’intégration » (Debré, 2003b : 11). C’est ainsi que «la défense de la liberté de conscience individuelle contre tout prosélytisme vient aujourd'hui compléter les notions de séparation et de neutralité centrales dans la loi de $1905 »$ (Stasi, 2003 : 14).

- Face à de telles politiques d'identité, on conclut à une exigence laïque qui demanderait «à chacun un effort sur soi » (ibid. : 16). Ceci vaudrait particulièrement pour l'élève qui ne serait pas « un simple usager du service public mais véritablement un individu titulaire de droits et soumis à des obligations» (Debré, 2003b: 16). Les élèves formeraient une " "communauté éducative" » avec leurs professeurs et devraient être conçus comme «des individus en construction dans une institution dont la mission est de les former» (ibid. : 30).

- Les commissions soutiennent que désormais, «la laïcité ne peut être conçue sans lien direct avec le principe d'égalité entre les sexes»(Stasi, 2003: 52). Un danger particulier est attribué au voile qui risquerait de «maintenir les femmes dans un statut social d'infériorité » 
(Debré, 2003a : 77), et qui devrait donc être interdit à l'école publique. Cette proposition est consacrée à l'Assemblée nationale le 15 mars 2004 avec une quasi-unanimité - 494 voix pour, 36 contre.

Quel rapport cette «nouvelle laïcité » entretient-elle avec l'arrangement historique et juridique que j’ai reconstruit plus haut? David Koussens soutient qu'elle a «consolidé un discours toujours plus identitaire d'une laïcité qui ne se situe plus simplement sur le plan des droits individuels qu'il faut garantir, mais aussi et surtout sur celui des valeurs (collectives) à promouvoir » (2015 : 179). Si la neutralité est « un indicateur des aménagements de la laïcité dans une société » (ibid. : 54), nécessaire parce que les principes laïques ne sont jamais parfaitement harmonisés, elle est ici particulièrement malmenée : le projet de loi et les débats parlementaires qui l'entourent se livrent à une interprétation des symboles religieux considérés comme dégradants (voile) et excessifs ou ostensibles (voile, kippa ou grande croix). L'aménagement de la laïcité qui est ainsi proposé transforme celui qui existait jusque-là : la hiérarchie entre la liberté de conscience et l'exigence de la séparation est inversée. De plus, l'exigence de neutralité est conçue comme un devoir individuel et élargie à l'ensemble de l'espace public, incluant la société civile (et non seulement l'État). Cette conception se retrouve également dans l'affirmation de la prérogative étatique, de son devoir moral de protéger les citoyens des pratiques religieuses musulmanes et du devoir missionnaire laïque de l'école qui vise l'émancipation des élèves de la religion et, plus fondamentalement, dans la volonté de définir la société politiquement. Il s'agit d'une conception de la laïcité qui la transforme davantage en religion civile et en "paternalisme d’État» (Laborde, 2012).

Pour ce qui est du droit, deux choses doivent être retenues. Premièrement, il faut noter qu'en 2003-2004, la « nouvelle laïcité » refuse, au moins dans sa version légale, de s'attaquer à son biais culturel qui porte atteinte à l'impératif de l'égalité de traitement. Ainsi, la commission experte, présidée par Bernard Stasi, a proposé un certain nombre de mesures par lesquelles les pouvoirs publics devraient «faciliter l'exercice des différents cultes» (Stasi, 2003: 62). Ces mesures sont censées réduire le privilège structurel du catholicisme dans le dispositif laïque par l'installation d'un enseignement du fait religieux dans les cours de français et d'histoire, la création d'une École nationale d'études islamiques, la compensation du manque d'aumôniers musulmans, la prise en compte des exigences religieuses en matière alimentaire et funéraire dans les services publics, ainsi que par l'introduction des fêtes juive et musulmane de Kippour et de l'Aïd-el-kébir dans le calendrier scolaire. Cependant, aucune de ces propositions n'est retenue dans la loi de 2004.

Deuxièmement, la représentation de la laïcité qui émerge au début du $21^{\text {ème }}$ siècle n'est pas sans effets sur la «laïcité juridique» comme l'illustre par exemple la jurisprudence du Conseil 
d'État concernant l'application de la loi de 2004. Le 5 décembre 2007, l’instance de juridiction administrative se prononce sur l'exclusion d'élèves sikhs et musulmanes portant la bandana, qualifiant foulard islamique, kippa, grande croix et keshi sikh (signe absent des considérations du législateur de 2004) comme signes manifestant ostensiblement une appartenance religieuse. Le changement de jurisprudence est notable : alors que le Conseil d'État affirmait le 27 novembre 1989 que le port de signe religieux n'était «pas par lui même » incompatible avec la laïcité (Décision $\mathrm{n}^{\circ} 346893$; nous soulignons), il conclut maintenant que le port de «signes ou tenues, tels notamment un voile ou un foulard islamique, une kippa ou une grande croix », manifeste "par luimême, [...] ostensiblement une appartenance religieuse » désormais interdite pour les élèves à l'école publique (Décision $n^{\circ} 285394$; nous soulignons). La bataille juridique à propos du licenciement d'une éducatrice de jeunes enfants revenant voilée sur son lieu de travail après cinq ans de congé de maternité qui se déroule entre 2010 et 2014 ( "l'affaire Baby Loup ») est un autre exemple de l'influence juridique grandissante de la «laïcité narrative». Les cinq différents jugements d'un conseil des prud'hommes, de deux cours d'appel et de la Cour de cassation font ressortir certains principes qui ne sont «pas congruent avec la signification du principe juridique de la laïcité » (Vauchez et Valentin, $2014: 29)$ : «l'injonction de neutralité religieuse non plus seulement à l'État mais aux personnes privées » (ibid. : 21), «l'idée d'une nécessaire neutralité de toute personne associée au service public, quel que soit son statut» (ibid. : 32), une interprétation d'un signe religieux emportant «le risque de le juger ostentatoire ou prosélyte sur des fondements essentiellement subjectifs ou aléatoires» (ibid. : 38) et «une conception éminemment substantielle de l'égalité, qui entend dépasser la seule défense de l'égalité en droit ou par le droit, pour contrôler la manière d'être égal » (ibid. : 65).

\section{La «laicité positive »}

Un des discours le plus remarqué du Président Nicolas Sarkozy, élu le 6 mai 2007, est celui qu’il prononce au Vatican en décembre de la même année. Il y introduit notamment le mot d'ordre de «laïcité positive», qui marque une évolution par rapport à la conception de la laïcité que l'orateur a défendue en tant que Ministre de l'Intérieur. Premièrement, par une prise de distance par rapport au culte musulman qui va de pair avec une « nationalisation » progressive de la laïcité, et deuxièmement, par un renforcement de l'idée d'une utilité sociale de la religion.

Comment expliquer une telle évolution? Par l'échec des ambitions hégémoniques de Nicolas Sarkozy sur le terrain de la laïcité, à savoir l'alliance politique avec des acteurs islamiques visant un apaisement religieux de la question sociale liée à l'immigration et la ségrégation territoriale. Cet échec se voit d'abord dans l'incapacité du CFCM et notamment de l'UOIF à jouer le rôle que le Ministre de l'Intérieur leur avait confié. Dès sa constitution et l'élection de ses 
membres en avril 2003, l'organe officiel de représentation du culte musulman est traversé par d'importantes luttes de pouvoir internes qui nuisent sérieusement à son bon fonctionnement. Celles-ci provoquent plusieurs interventions directes de Nicolas Sarkozy pour garantir l'existence même de l'instance. Se rajoutent à cela des problèmes de représentativité, la base militante de l'UOIF restant « sceptique par rapport à la défense de ses intérêts par le CFCM » (Frégosi, 2008 : 315). L'interdiction des signes religieux à l'école cause par ailleurs une désillusion profonde et met publiquement « en évidence l'existence d'un clivage entre les membres cooptés du bureau - qui déconseillèrent la manifestation du 17 janvier 2004 - et les élus qui y participèrent » (Sellam, 2006 : 299). Enfin, à chaque élection, l'UOIF perd des voix au profit des organisations musulmanes dépendantes des États nord-africains, faisant ainsi régresser le CFCM vers le modèle historique de représentation de l'islam, dominé par les relais des ambassades concernées. C'est cependant précisément pour aller à l'encontre de telles structures que le CFCM a initialement été créé.

A ces problèmes internes s'ajoutent des pressions extérieures: les opposants de la politique sarkozyenne au sein de la droite essayent d'affaiblir le CFCM. Ainsi, Dominique de Villepin, successeur de Nicolas Sarkozy au Ministère de l'Intérieur en mars 2004, propose, en novembre de la même année, la création du Conseil représentatif des institutions musulmanes (CRIM) à l'instar du Conseil représentatif des institutions juives de France (CRIF) « contrebalançant ainsi le poids des représentants fondamentalistes du CFCM » (Zeghal, 2005 : 110). De plus, la place Beauvau crée, en mars 2005, la Fondation pour les œuvres de l'islam. A en croire un acteur du débat sur la laïcité d'alors, le futur Premier Ministre socialiste, Manuel Valls, cette structure censée centraliser la collecte des dons pour le culte musulman en France (construction de mosquées, formation des imams et des aumôniers, et ainsi de suite.), n'est rien moins qu' « une remise en cause du CFCM » (Valls, $2005: 116)$.

La crise du CFCM, et notamment celle de l'UOIF, se transforment en véritable échec à l'automne 2005 quand l'organisation musulmane s'avère incapable de pacifier les révoltes des quartiers populaires, une tâche que Nicolas Sarkozy lui avait attribué. Ainsi, la fatwa contre la participation musulmane promulguée par l'UOIF devient surtout un objet de moquerie parmi les personnes visées : l'organisation musulmane «n'était en position ni d'étouffer une révolte aussi radicale ni d'en tirer parti», observe Hugues Lagrange. «Elle bénéficie d'une audience certaine, mais elle n'a pas une forte capacité d'organisation et d'action dans les cités. [...] Force est de constater que les leaders religieux n'ont pas eu beaucoup plus de succès dans leurs tentatives de retenir les émeutiers que les leaders associatifs non religieux. [...] Les religieux musulmans n'ont ni favorisé le développement des émeutes, ni véritablement éteint le feu.» (2008 : 390 passim) Le manque d'ancrage social en apparaît comme la raison principale. 
L'incapacité à «insuffler la vie» au CFCM et à calmer la contestation socio-politique amène Nicolas Sarkozy à se distancier de plus en plus des organisations musulmanes dès la fin de l'année 2005. Ainsi, son initiative de reformer la loi de 1905 pour pouvoir financer publiquement mosquées et carrés musulmans dans les cimetières (Machelon, 2006), lancée peu avant les révoltes de 2005, reste sans suite. Puis, revenant au Ministère de l'Intérieur en juin 2005, le futur Président défend publiquement la revue Charlie Hebdo qui reproduit en février 2006 les caricatures controversées de Mahomet parues dans le journal danois Jyllands Posten, tandis que la GMP et l'UOIF essaient en vain d'empêcher juridiquement leur publication. Le désaccord atteint son paroxysme quand l'UOIF appelle à voter François Bayrou, le candidat centriste à la présidentielle de 2007. Selon un sondage réalisé à la sortie des urnes, seulement un pour cent des musulmans de France vote finalement pour le candidat de droite en avril 2007, et seuls six pour cent le font au deuxième tour deux semaines plus tard.

Déjà pendant la campagne électorale, Nicolas Sarkozy «évoque les religions juive, catholique et protestante comme des composantes légitimes de l'identité française, mais n'a pas un seul mot à l'égard de la religion musulmane» (Noiriel, 2007 : 97). Au contraire, en février 2007, le candidat de l'UMP (Union pour un mouvement populaire) déclare qu'en France, « on n'est pas polygame, on ne pratique pas l'excision sur ses filles, on n'égorge pas le mouton dans son appartement et on respecte les règles républicaines» (cité dans Andrault, 2008: 55), suggérant ainsi une contradiction entre l'identité nationale et l'islam. Puis, par de nombreuses références médiévalo-chrétiennes, le candidat vise «à recouvrir les acquis de la laïcité politique par la fiction d'une France “fille aînée de l’Église” » (Madeline et Potin, 2008 : 88).

$\mathrm{La}$ «catholisation du discours sarkozyen » (ibid.) répond non seulement à la volonté de valoriser l'identité nationale en soulignant tout particulièrement son élément chrétien. Cette orientation de la campagne électorale tient également à la nouvelle «visibilité » (Haegel, 2012 : 231) que les catholiques acquièrent avec la fondation de l'UMP en 2002 et exprime donc un recentrage de l'ambition hégémonique sur des alliances plus classiques de la droite française. De nombreux militants de l'Union pour la démocratie française (UDF), pour qui le facteur religieux est d'une grande importance (Fretel, 2004), sont en effet intégrés dans le nouveau parti, auxquels s'ajoute « la structuration de la sensibilité catholique au sein de l’UMP» (Haegel, 2009: 22) par Christine Boutin. De plus, Nicolas Sarkozy doit sa victoire électorale au moins partiellement à la «mobilisation des milieux catholiques en sa faveur» (Haegel, 2012 : 232). Emmanuelle Mignon, énarque qui travaille depuis 2002 auprès de lui, d'abord à l'Intérieur, puis à l'UMP, constitue un relais privilégié de cette sensibilité (Mignon, 2007). Celle-ci incarne le prototype des « catholiques d'identité », cette frange du catholicisme français qui essaie depuis les années 1970 de rétablir la 
direction de l'Église dans les affaires sociétales, notamment par l'engagement social, face à la pluralisation et l'individualisation de la foi « d'en bas » (Portier, 2008b : 27 passim).

Emmanuelle Mignon est ainsi l'auteure du discours dit « de Latran» de décembre 2007, déjà évoqué, dans lequel Nicolas Sarkozy invoque une «laïcité positive» (Sarkozy, 2007), caractérisée notamment par l'idée de l'utilité sociale de la religion : «La désaffection progressive des paroisses rurales, le désert spirituel des banlieues, la disparition des patronages, la pénurie de prêtres, n'ont pas rendu les Français plus heureux. [...] La République a intérêt à ce qu'il existe aussi une réflexion morale inspirée de convictions religieuses. D’abord parce que la morale laïque risque toujours de s'épuiser quand elle n'est pas adossée à une espérance qui comble l'aspiration à l'infini. Ensuite et surtout parce qu'une morale dépourvue de liens avec la transcendance est davantage exposée aux contingences historiques et finalement à la facilité »(ibid.). Dans la transmission des valeurs, «l'instituteur ne pourra jamais remplacer le curé ou le pasteur » (ibid.), affirme ainsi le nouveau Président, slogan abondamment repris par les médias.

Cette vision semble en fait plus proche d'une conception gallicane que laïque du rapport entre État et religions. Elle trouve son expression dans la tentative d'adjoindre à la laïcité un suffixe tel que «élargie », " ouverte » ou « positive », qui exprime la revendication d'un rôle plus actif de la religion dans les affaires sociales et politiques. Cet effort représente par ailleurs une constante dans le discours théologique du catholicisme français depuis les années $1940^{13}$. Le Président de la République fait sien ce combat en déclarant que la conception originelle et libérale de la laïcité est sujette à caution : «Je sais que l'interprétation de la loi de 1905 comme un texte de liberté, de tolérance, de neutralité est en partie [...] une reconstruction rétrospective du passé » (ibid.). L'«adhésion explicite à la loi du 15 mars 2004 sur l'interdiction des signes religieux à l'école publique » (Portier, 2008a : 197) dont témoigne de surcroît ce discours, dissimule ainsi la résistance initiale de Nicolas Sarkozy à la prohibition de tels signes et l'échec de l'ambition hégémonique qui le propulsait entre 2002 et 2005. Mais cette prise de position montre surtout qu'en matière de laïcité, il y a désormais un double standard: une laïcité restrictive pour les musulmans, une laïcité « positive » pour les catholiques.

\section{La «laïité falsifiée »}

Tandis que la «laïcité positive» entretient des liens pour le moins tendus avec la laïcité historique, la deuxième moitié du mandat présidentiel de Nicolas Sarkozy ne donne guère à voir de détente en la matière. Au contraire, on observe un développement que certains ont pu qualifier de «falsification» de la laïcité (Baubérot, 2012). Il s'agit là d’une radicalisation des représentations sociales qui s’imposent contre les ambitions hégémoniques initiales de la droite sarkozyenne. Le projet d'une nouvelle alliance politique avec des acteurs islamiques propulsé par 
Nicolas Sarkozy est maintenant non seulement au point mort, mais le Président n'est aussi plus vraiment acteur du développement idéologique que subit la laïcité. Trois évènements survenant dans cette période viennent lui donner corps : l'interdiction du voile intégral, le débat de l'UMP sur la laïcité et enfin son appropriation par l'extrême droite.

L'attention médiatique pour le voile intégral en été 2009 découle notamment d'une campagne politique du président du groupe UMP à l'Assemblée nationale, Jean-François Copé ${ }^{14}$. Celui-ci s'appuie sur l'initiative d'interdiction du député communiste et maire de Vénissieux, André Guérin, pour «s'imposer dans sa famille politique comme un vrai chef de guerre. Un combattant et un meneur d'hommes dont personne ne pourra contester, le moment venu, qu'il peut prétendre succéder à Nicolas Sarkozy » (Auffray, 2011: 70). Le concurrent du Président dans sa propre formation politique réussit ainsi à installer une mission d'information parlementaire sur la pratique du voile intégral en France qui rend son rapport fin janvier 2010 (Raoult, 2010). «En écartant le témoignage des principales intéressées » (Borghée, 2012 : 205), cette mission ne s'appuie pas sur le travail des ligues laïques historiques (à l'exception de la loge maçonnique du Grand Orient de France), mais procède au contraire à nombreuses auditions d'associations qui « ont été créées après 1989, dans la configuration du conflit entre la laïcité et un certain islam» (Baubérot et Milot, 2011: 302), dont certains groupuscules d'extrême droite comme Riposte lä̈que. L'enquête sur une pratique vestimentaire marginale (le Ministère de l'Intérieur rapporte en juillet 2009 le cas de 367 femmes portant le voile intégral sur tout le territoire national, tandis que la commission en affiche 1 900) et mal comprise ${ }^{15}$ présente ainsi l'occasion de radicaliser la «nouvelle laïcité». Les quatre registres évoqués plus haut en témoignent :

- La mission propose une inscription du principe de laïcité dans le droit relatif aux étrangers et à la nationalité pour réprimer la pratique du voile intégral (Raoult, 2010 : 163-166), faisant ainsi de cette interdiction une question d'identité nationale. Cette proposition est particulièrement biaisée pour deux raisons. Premièrement, parce que le port du voile intégral concerne souvent des converties sans lien familial avec l'immigration, et deuxièmement, parce qu'il est fortement dû aux dynamiques intrinsèques de la société française et non à une identité musulmane monolithique (Borghée, 2012 : 108-117 ; 133-144) ${ }^{16}$.

- Suivant l'exemple des discours des années 2003-2004, la mission conçoit le port du voile intégral comme une politique d'identité musulmane dont le but serait de faire pression sur l'entourage non voilé. Plus encore, on aurait affaire à une infraction à la devise républicaine de liberté (de se vêtir et de disposer de son propre corps), d'égalité (par l'annihilation de la personnalité et le refus de l'égale dignité) et de fraternité (nécessitant le lien social créé par l’interaction en face à face) (Raoult, 2010 : 95-122). 
- Le glissement conceptuel le plus remarquable se trouve sans doute dans l'élargissement du domaine d'application de l'exigence de neutralité. La mission l'identifie à un devoir avant tout individuel et à un particularisme ethnico-culturel : «le principe de laïcité interdit à quiconque de se prévaloir de ses croyances religieuses pour s'affranchir des règles communes régissant les relations entre collectivités publiques et particuliers. La République respecte bien toutes les croyances mais, en contrepartie, les citoyens doivent aussi respecter un devoir de discrétion dans l'extériorisation de leurs convictions religieuses. Comme le soulignait M. Patrice Billaud, viceprésident du Grand Orient de France : "Dans l'espace public, la liberté individuelle doit s'exprimer dans les limites culturelles de la communauté nationale à une période donnée" » (ibid: 89). Il semble que la mission est tout à fait consciente du fait que sa réarticulation des principes laïques ne peut que difficilement se revendiquer de l'héritage historique de la loi de 1905. En tout cas, l'institution parlementaire soutient que «le port du voile intégral dans l'espace public n'est pas, en soi, une atteinte au principe de laïcité juridiquement parlant » car le respect de ce principe « s'impose aux collectivités publiques et non aux individus ». La pratique en question serait plutôt « une atteinte à la laïcité au sens philosophique du terme plus qu’au sens juridique » (ibid. : 93).

- Enfin, la dimension du genre est explicite dans le travail opéré par la mission. Ainsi, elle conçoit le voile intégral comme « une marque d'apartheid sexuel» (ibid. : 109) et revendique une meilleure protection des femmes par des lois et institutions existantes (ibid. : 144-146 ; 150-154).

Cette reformulation de la laïcité est beaucoup moins consensuelle que celle des années 2003-2004. Ainsi, les laïques de gauche tels que le philosophe Henri Pena-Ruiz et la journaliste Caroline Fourest contestent dans leurs auditions respectives l'évocation de la laïcité pour interdire le voile intégral (ibid. : 492-509). Le rapporteur de la commission Stasi, Rémy Schwartz, évoque pour sa part une atteinte aux principes constitutionnels (ibid. : 386-389). De plus, au moment du vote parlementaire, les députés de gauche quittent quasi unanimement la salle en dénonçant, selon les dires de Jean Glavany, le spécialiste des questions de laïcité au Parti socialiste, «les arrière-pensées antimusulmanes primaires » (2011: 188) des promoteurs de la loi. Encore plus frappant apparaît le désaccord au sein de la droite que le journaliste Alain Auffray décrit de la manière suivante : «beaucoup de parlementaires de la majorité n’en peuvent plus. Des burqas, ils n'en ont jamais vues ni de près ni de loin dans leurs circonscriptions. Et jamais un électeur ne les a interrogés sur le sujet. Au moment où le gouvernement s'empêtre dans un débat pathétique sur l'identité nationale, certains ne cachent pas leur exaspération. "Le rôle des responsables politiques, c'est aussi de mettre la sérénité pas d'agiter les peurs. Nous sommes quelques-uns à en avoir par-dessus la tête. Depuis des mois, on ne parle plus que de ces quelques centaines de femmes bâchées”, se désespère le savoyard Hervé Gaymard » (2011 : 75).

Il n'empêche, cette laïcité reformulée est consacrée par l'Assemblée nationale (et par le 
Sénat lors de sa lecture du 13 juillet 2010) avec la loi du 11 octobre 2010 interdisant la dissimulation du visage dans l'espace publique, «constitué des voies publiques ainsi que des lieux ouverts au public ou affectés à un service public » (art. 2).

Encouragé par son succès, Jean-François Copé propose en février 2011 la tenue d'un grand débat sur la laïcité à l'instar de celui que le Ministre de l'Immigration, l'Intégration, l'Identité nationale et le Développement solidaire, Éric Besson, avait lancé à la fin de l'année 2009. La proposition de ce nouveau débat amplifie encore les clivages au sein du parti présidentiel. L’ancien Premier Ministre, Jean-Pierre Raffarin, estime que l’idée du président du groupe parlementaire de droite constitue «une connerie monstre qui trahit une inculture fondamentale» (cité dans Auffray, 2011: 81) exposant l’UMP au risque d'une scission. De nombreuses personnalités de droite tel que le président de l'Assemblée nationale, Bernard Accoyer, l'ancienne ministre Rama Yade et l'architecte de la « nouvelle laïcité », François Baroin, manifestent publiquement leur désapprobation. Puis, dans un appel publié le 29 mars 2011 dans le journal Le Parisien, les représentants des six grandes religions de France évoquent « des risques de stigmatisation » de l'islam.

Le débat qui est finalement organisé en avril 2011 se résume à deux tables rondes qui se tiennent dans un hôtel parisien pour un public restreint (journalistes, militants et responsables politiques). Les échanges ne durent que trois heures et demie. La première table ronde est intitulée « La laïcité au $\mathrm{XXI}^{\mathrm{e}}$ siècle : un modèle français ? ", la deuxième se concentre sur laïcité et islam et se termine au bout d'une heure. A ce moment-là, la plupart des députés et des ministres de l'UMP (seul un tiers des membres du gouvernement s'est déplacé) ont déjà quitté la salle. Les représentants des religions présents comme le Grand Rabbin de France, Gilles Bernheim, ont quant à eux gagné les rangs des spectateurs à ce moment-là, par souci de ne pas s'ériger en juges d'une religion qui n'est pas la leur. Il est significatif qu'aucune organisation membre du CFCM n'a envoyé de représentants.

Alors que le déroulement de la manifestation trahit un échec, la synthèse idéologique qui en ressort tourne le dos à l'arrangement historique de la laïcité. Ainsi, le parti présidentiel veut « éviter que les ministres du culte aient un lien de subordination avec un État étranger »(UMP, 2011 : 15) - une initiative qui vise de toute évidence implicitement le culte musulman. Cependant, ce type de proposition est tellement restrictif qu'il nuirait plus généralement à l'exercice du culte en France, comme le soutient Jean Baubérot: «En effet, seuls les prêtres, subordonnés à un évêque, lui-même subordonné au pape, ont le droit de célébrer l'eucharistie, indispensable pour qu'il s'agisse d'une messe [...]. Donc si on veut réellement "éviter" ce "lien de subordination" [...] cette mesure aura comme effet pratique d'interdire la messe en France» (2011). De plus, la proposition d'« étendre les obligations de neutralité qui s’imposent dans les structures publiques, 
aux structures privées des secteurs social, médico-social ou de la petite enfance chargées d'une mission de service public ou d'intérêt général »(UMP, 2011: 8 passim) reviendrait à exclure des femmes portant le voile d'un large secteur du marché de travail. Enfin, l'UMP réaffirme la laïcité à deux vitesses que j’ai évoquée plus haut. Ainsi, le texte évoque à plusieurs reprises la «liberté religieuse » (et non pas la liberté de conscience), véritable topos du discours de la «laïcité positive » qui permet de rassurer les catholiques tout en manifestant une claire intransigeance à l'égard des musulmans. Malgré ces incohérences, les vingt-six propositions de l'UMP font l'objet d'une résolution parlementaire non contraignante votée par la majorité en juin 2011.

Pour Jean Baubérot, le débat de l'UMP «constitue l'aboutissement d'un processus marqué notamment par un rapport, fondamental bien que relativement méconnu, dans lequel François Baroin prône une "nouvelle laïcité" jusqu’à un certain point "incompatible" avec les droits de l'homme» (2012: 8). Cependant, cette manifestation n’en est pas la dernière étape. Celle-ci consiste dans l'appropriation de la laïcité par son ennemi historique, à savoir l'extrême droite.

On mesure bien le chemin idéologique parcouru par cette formation politique en se rappelant l'audition de Bruno Gollnisch devant la commission Stasi en octobre 2003. A l'époque, le secrétaire général du FN se prononce pour une interdiction du voile à l'école publique par décret ministériel pour des raisons d'hygiène et de sécurité, mais non de laïcité. Il a fallu l'ascension politique de la députée européenne Marine Le Pen et la stratégie de « dédiabolisation » de son parti pour que celui-ci commence à s'y référer positivement. «C'est sans doute là la métamorphose la plus spectaculaire entreprise par le nouveau Front national» estime Renaud Dély (2012 : 168). Et c'est aussi la raison pour laquelle de nombreuses personnalités du milieu ultra-catholique quittent le parti par la suite.

L'appropriation frontiste de la laïcité débute avec une campagne contre les prières musulmanes dans la rue que Marine Le Pen, dans une interview en décembre 2010, n’hésite pas à assimiler à l'occupation allemande ${ }^{17}$. Par la suite, on assiste à une surmédiatisation du phénomène au point où l'on peut à nouveau parler d'une «panique morale»: une pratique marginale est présentée comme une mise en péril des valeurs sociales, en l'occurrence de la laïcité. «Résultat des courses: en mai [2011], l'institut Harris Interactive effectue un sondage. À la question ouverte: "Selon vous, combien y a-t-il en France de rues dans lesquelles les musulmans prient le vendredi ?", le chiffre moyen donné par les sondés est... cent quatre-vingt-cinq! Cent quatrevingt-cinq lieux de prière : un chiffre qui non seulement n'a rien à voir avec la réalité, mais même avec ce que Marine Le Pen elle-même a prétendu » (Baubérot, 2012 : 20). La future présidente du FN avait en effet parlé de dix ou quinze endroits concernés fin 2010 ; le CFCM estime son nombre à moins de dix à l'époque. 
La croisade morale contre les prières de rue n'est pas seulement efficace en ce qu'elle parvient à imposer l'idée trompeuse d'un «problème» omniprésent. Elle réussit aussi plus profondément à diffuser une conception antimusulmane de la laïcité. Ainsi, Marine Le Pen soutient «que la France peut être läque parce qu'elle est chrétienne de culture, et on s'aperçoit d'ailleurs que les pays musulmans ont les plus grandes difficultés à être laïcs [...]. La laïcité n'est pas absolument compatible... pas naturelle, avec l'islam, puisque l'islam confond le spirituel et le temporel» (Le Pen, 2011). Les propositions par lesquelles la présidente du FN se fait entendre par la suite, telles que l'interdiction de l'abattage halal ou celle de l'UOIF, vont également dans le sens d'une restriction de la vie cultuelle musulmane. De plus, le programme du FN pour l'élection présidentielle de 2012 évoque « une laïcité à laquelle nous sommes profondément attachés » (FN, 2012) et que le parti souhaite réaffirmer par des réformes symboliques et répressives: amendement de la Constitution («La République ne reconnaît aucune communauté »; ibid.), institution d'un «ministère de l'Intérieur, de l'Immigration et de la Laïcité » (ibid.) et enfin, interdiction de porter des signes religieux ostentatoires pour les agents comme les usagers des services publics, transports publics compris.

Ces idées s'inscrivent pleinement dans les transformations de la laïcité que j’ai observée. Elles font d'abord écho à la tendance à élargir l'exigence de neutralité à la société civile. Dans le cas des prières de rue, cette stratégie passe par une «territorialisation » de la laïcité (Arêas, 2014). De plus, les conceptions décrites font preuve d'une concentration exclusive sur l'islam. Le contraste avec des pratiques comparables de la part du culte majoritaire le montre bien : durant l'hiver 2012-2013, les nombreuses prières catholiques publiquement célébrées dans le cadre du mouvement contre le projet de loi instaurant le mariage de couples de personnes de même sexe ne font l'objet d'aucune contestation ni intervention des pouvoirs publics.

L'efficacité idéologique de la conception de la laïcité avancée par l'extrême droite se mesure également par le brouillage des frontières politiques qu'elle occasionne. Par exemple, la philosophe Elisabeth Badinter, marquée à gauche, déplore qu'« en dehors de Marine Le Pen, plus personne ne défend la laïcité » (2011 : 35). Puis, en septembre 2011, le Ministre de l'Intérieur, Claude Guéant, soutient que la prière de rue «n'est pas digne d'une pratique religieuse et contrevient au principe de la laïcité » (cité dans Denizeau, 2014 : 127) avant d'interdire cette pratique par la suite ${ }^{18}$.

\section{Nouvelle laïcité, luttes politiques et changement d'action publique}

Les transformations que cet article s'est efforcé de mettre en évidence traduisent une évolution profonde de la vie politique française. Tout d'abord, on peut observer, dans la conjoncture politique dont j'ai proposé l'analyse, plusieurs mises en «narration » de la laïcité, 
c'est-à-dire l'émergence de différentes représentations de celle-ci. Elles sont mobilisées pour appuyer des stratégies politiques divergentes, mais l'arrangement qui s'impose finalement est une forme radicalisée de ce qui a été appelée «nouvelle laïcité »: une règlementation des pratiques cultuelles transformée en identité nationale, faisant de la laïcité une valeur morale à laquelle est demandée l'adhésion notamment par des populations descendantes de l'immigration de pays musulmans ; un défi particulier qui résulterait des pratiques identitaires musulmanes, notamment vestimentaires, conçues comme étant opposées au modèle républicain; l'individualisation de l'exigence de neutralité religieuse notamment envers le culte musulman ainsi que l'extension de cette exigence à un espace public conçu largement; et enfin, une laïcité comme outil d'instauration de l'égalité entre les sexes. Cette «nouvelle laïcité» impacte concrètement sur l'articulation législative et juridique de la laïcité. Elle s'inscrit certainement dans l'histoire de la régulation du rapport entre État et cultes en France en ce qu'elle accentue le libéralisme ambigu et culturellement biaisé qui caractérise la laïcité depuis sa solidification dans la III ${ }^{\text {̀̀me }}$ République. Étant ainsi particulièrement paternaliste et focalisée sur l'islam, la «nouvelle laïcité » appuie cependant un vrai changement dans l'action publique, c'est-à-dire de ses mesures, objectifs, cadres normatifs d'orientation, instruments et cadres institutionnels (Muller, 2005 : 156 passim).

Mon analyse confirme donc l'importance des représentations sociales dans ce changement telle qu'elle est défendue par les Cultural Studies britanniques et l'analyse cognitive des politiques publiques. Pierre Muller soutient ainsi que «la mise en œuvre du changement politique passe nécessairement par la définition d'une représentation imposée/acceptée de l'avenir du domaine ou du secteur qui fait l'objet de la politique ; cette vision constitue à la fois le cadre et l'enjeu des confrontations des différents acteurs qui vont entrer dans des relations de coopération et/ou d'affrontement dans les différents forums et arènes du secteur concerné » (ibid. : 169). J'ai souligné l'importance des «paniques morales» (autour des «jeunes de banlieue», du foulard à l'école publique, du voile intégral sur la voie publique et de la prière de rue) en tant qu'expressions de crises politiques. Travailler et diffuser des représentations sociales pour imposer certaines solutions à des « crises » préalablement construites n'est pas un acte neutre. Au contraire, il s'agit d'une lutte de resignification au sens de Stuart Hall (2012) ou, dans les termes de Pierre Muller, de l'élaboration d'un nouveau cadrage cognitif (identification de nouveaux problèmes/enjeux laïcs) et normatif (justification de nouvelles actions publiques).

Il me semble que c'est la dynamique des luttes politiques qui animent ces glissements idéologiques qui n’a pas encore été suffisamment exploré par les spécialistes qui ont observés les transformations récentes de la laïcité. J'ai proposé de les saisir dans le cadre des ambitions hégémoniques de la droite française entre 2002 et 2012. Contrairement à ce qu'on retient souvent de l'action politique de Nicolas Sarkozy et la «droitisation» du discours présidentiel (Mayaffre, 
2012), ce sont plutôt les oppositions au et l'échec du programme politique initialement poursuivi par lui qui mènent à la réarticulation de la laïcité observée ici.

Reste à retenir que l'héritage colonial de la gestion publique du culte musulman en France indique toutefois que les développements analysés échappent à une pure histoire de la laïcité. Des recherches ultérieures doivent établir si ces processus ne seraient pas à comprendre aussi par une analyse des représentations racistes, avant d'être recherchées dans l'étude des rapports entre politique et religieux (pour un début de tentative en ce sens Hajjat et Mohammed 2016 ; Moussa 2017).

\section{References}

Andrault, Marc. 2008. Sarkozy et dieu. De l'usage politique des monothéismes. Paris : Berg International.

Arêas, Camila. 2014. «La politisation des espaces dans les territoires laïcs de la République française. Analyse du débat autour de la "petite phrase" de Marine Le Pen sur la prière de rue musulmane ». Dans Lambert, 2014 : 95-114.

Artufel, Claire et Marlène Duroux. 2006. Nicolas Sarkozy et la communication. Paris : Editions Pepper.

Asad, Talal. 2003. Formations of the Secular. Christianity, Islam, Modernity. Stanford: Stanfort University Press.

Auffray, Alain. 2011. Les loups et les chiens. La droite sous Sarkozy. Paris : Éditions du Moment.

Badinter, Élisabeth. 2011. " "Une crise profonde mais fructueuse” ». Le Monde des religions 49 : 3335.

Balibar, Étienne. 2012. «Laizität». Dans Historisch-kritisches Wörterbuch des Marxismus, tome 8.1, dir. Frigga Haug, Wolfgang F. Haug, Peter Jehle et Wolfgang Küttler. Hambourg: Argument, 616-631.

Baroin, François. 2003. Pour une nowvelle laïcité. <http://www.voltairenet.org/rubrique506.html?lang=fr> (consulté le 28 août 2018).

Baubérot, Jean. 2004. Lä̈ité 1905-2005, entre passion et raison. Paris : Seuil.

Baubérot, Jean. 2006. L'intégrisme républicain contre la laicité. La Tour d'Aigues : Éditions de l'aube, 179-183.

Baubérot, Jean. 2008. " "Dialogue avec l'abstentionniste de la commission Stasi”. Entretien avec Jean Baubérot ». Droit et société 68 (1) : 237-249.

Baubérot, Jean. 2011. «L'UMP voudrait interdire la messe en France». <http://jeanbauberotlaicite.blogspirit.com/archive/2011/05/10/1-ump-voudraitinterdire-la-messe-en-france.html> (consulté le 28 août 2018). 
Baubérot, Jean. 2012. La laïcité falsifiée. Paris : La découverte.

Baubérot, Jean et Micheline Milot. 2011. Laïcités sans frontières. Paris : Seuil.

Borghée, Maryam. 2012. Voile intégral en France. Sociologie d'un paradoxe. Paris : Michalon.

Bozzo, Anna. 2006. "Islam et citoyenneté en Algérie sous la $\mathrm{III}^{\mathrm{e}}$ République: logiques et contradictions coloniales (l'exemple des lois de 1901 et 1905)». Dans Luizard, 2006a : 197-222.

Confavreux, Joseph et Jade Lindgaard. 2007. «L'hémisphère droit. Comme la droite est devenue intelligente ». Mouvements. Des idées et des luttes $52: 14-34$.

Constantini, Dino. 2008. Mission civilisatrice. Le rôle de l'histoire coloniale dans la construction de l'identité politique française. Paris : La découverte.

Davidson, Naomi. 2012. Only Muslim. Embodying Islam in Twentieth-Century France. New York: Cornell University Press.

Debré, Jean-Louis, dir. 2003a. Rapport sur la question du port des signes religieux à l'école, tome I - $1^{\text {ère }}$ partie. <http://www.assemblee-nationale.fr/12/rapports/r1275-t1.asp> (consulté le 28 août 2018).

Debré, Jean-Louis, dir. 2003b. Rapport sur la question du port des signes religieux à l'école, tome I - 2 ${ }^{\text {ème }}$ partie. <http://www.assemblee-nationale.fr/12/rapports/r1275-t1-2.asp> (consulté le 28 août 2018).

Deltombe, Thomas. 2005. L'islam imaginaire. La construction médiatique de l'islamophobie en France 1975-2005. Paris : La découverte.

Dély, Renaud. 2012. La droite brune. UMP-FN : les secrets d'une liaison fatale. Paris : Flammarion.

Denizeau, Charlotte. 2014. «Les prières de rue saisies par le droit public ». Dans Lambert 2014 : 115-135.

Dimier, Véronique. 2001. «La laïcité : un produit d'exportation? Le cas du rapport Combes (1892) sur l'enseignement primaire indigène en Algérie ». Dans La laïcité, une valeur aujourd'bui? Contestations et renégociations du modèle français, dir. Jean Baudouin et Philippe Portier. Rennes : Presses Universitaires de Rennes, 65-82.

Encrevé, André, Jacques Gadille et Jean-Marie Mayeur. 1995. «La France ». Dans Histoire du christianisme des origines à nos jours, tome XI, dir. Jacques Gadille et Jean-Marie Mayeur. Paris : Desclée, 509-519.

Frégosi, Franck. 2008. Penser l'islam dans la laïcité. Les musulmans de France et la République. Paris : Fayard.

Fretel, Julien. 2004. "Quand les catholiques vont au parti. De la constitution d'une illusio paradoxale et du passage à l'acte chez les "militants" de l'UDF». Actes de la recherche en sciences sociales 155 : 76-89. 
Front National (FN). 2012. Projet du FN sur la lä̈ité. <http:// sita.over-blog.org/article-projet-dufn-sur-la-laicite-89574537.html> (consulté le 28 août 2018).

Geisser, Vincent et Aziz Zemouri. 2007. Marianne \& Allah. Les politiques français face à la « question musulmane ». Paris : La découverte.

Glavany, Jean. 2011. La Laïcité. Un combat pour la paix. Paris : Éditions Héloïse d’Ormesson.

Gresh, Alain. 2004. L'islam, la République et le monde. Paris : Fayard.

Gramsci, Antonio. 1978. Cabiers de prison. Cabiers 10, 11, 12 et 13. Paris : Gallimard.

Guénif-Souilamas, Nacira et Éric Macé. 2006. Les féministes et le garçon arabe. La Tour d'Aigues : Éditions de l'aube.

Haegel, Florence. 2009. «La mobilisation partisane de droite. Les logiques organisationnelles et sociales d'adhésion à l'UMP ». Revue française de science politique 59 (1) : 7-27.

Haegel, Florence. 2012. Les droites en fusion. Transformations de l'UMP. Paris : Presses de Sciences Po.

Hajjat, Abdellali et Marwan Mohammed. 2016. L'islamophobie. Comment les élites françaises fabriquent le "problème musulman ». Paris : La découverte.

Hall, Stuart. 2012. «Signification, représentation, idéologie: Althusser et les débats poststructuralistes ». Raisons Politiques. Etudes de pensée politique 48 : 131-162.

Hall, Stuart et Chas Critcher, Tony Jefferson, John Clarke et Brian Roberts. 1978. Policing the Crisis. Mugging, the State, and Law and Order. Londres : MacMillan.

Icard, Philippe. 2005. «L'évolution de la jurisprudence administrative dans l'application de la loi du 9 décembre 1905 (le point de vue d'un juriste)». Dans 1905 ! La loi de séparation des Églises et de l'État, dir. Jean-Marc Schiappa. Paris : Syllepse, 569-602.

Jobert, Bruno et Pierre Muller. 1987. L'état en action. Politique publiques et corporatismes. Paris : PUF.

Kepel, Gilles. 1987. Les banlieues de l'islam. Naissance d'une religion en France. Paris : Seuil.

Koussens, David. 2015. L'épreuve de la neutralité. La laïcité française entre droits et discours. Bruxelles: Éditions Bruylant.

Laborde, Cécile. 2012. «State paternalism and religious dress code». International Journal of constitutional law 10 (2) : 398-410.

Lagrange, Hugues. 2008. «Émeutes, ségrégation urbaine et aliénation politique ». Revue française de science politique 58 (3) : 377-401.

Lambert, Frédéric, dir. 2014. Prières et Propagandes. Études sur la prière dans les arènes publiques. Paris : Éditions Hermann.

Le Pen, Marine. 2011. «Marine Le Pen donne sa définition d'une France lä̈que ». Le Parisien en ligne, 28 janvier. <http://www.leparisien.fr/election-presidentielle-2012/marine-le-pen- 
donne-sa-definition-d-une-france-laique-28-01-2011-1247059.php> (consulté le 28 août 2018).

Lindner, Kolja. 2017. Die Hegemoniekämpfe in Frankreich. Laiæismus, politische Repräsentation und Sarkozysmus. Hambourg: Argument.

Lindner, Kolja. A paraître. «'Muddled thinking' : Stuart Hall et la théorie d'hégémonie ». Dans L'optimisme de la volonté. Stuart Hall, une sentinelle critique pour une bégémonie de gauche, dir. Malek Bouyahia, Franck Freitas et Karima Ramdani. Paris : La dispute.

Luizard, Pierre-Jean, dir. 2006a. Le choc colonial et l'islam. Les politiques religieuses et puissances coloniales en terre d'islam. Paris : La découverte.

Luizard, Pierre-Jean. 2006b. «La politique coloniale de Jules Ferry en Algérie et en Tunisie». Dans Luizard, 2006a : 89-120.

Macé, Éric. 2002. «Le traitement médiatique de la sécurité ». Dans Crime et sécurité. L'état des savoirs, dir. Laurent Mucchielli et Philippe Robert. Paris : La découverte, 33-41.

Machelon, Jean-Pierre. 1976. La République contre les libertés? Les restrictions aux libertés publiques de 1879 à 1914. Paris : Presses de Sciences Po.

Machelon, Jean-Pierre, dir. 2006. Les relations des cultes avec les pouvoirs politiques. $<$ http://www.ladocumentationfrancaise.fr/var/storage/rapportspublics/064000727.pdf> (consulté le 28 août 2018).

Madeline, Fanny et Yann Potin. 2008. « Fille aînée de l'Église ». Dans Comment Nicolas Sarkosy écrit l'histoire de France, dir. Laurence de Cock, Fanny Madeline, Nicolas Offenstadt et Sophie Wahnich. Marseille : Agone, 87-90.

Mamdani, Mahmood. 2004. Good Muslim, Bad Muslim. America, the Cold War and the Roots of Terror. New York : Pantheon Books.

Mayaffre, Damon. 2012. Nicolas Sarkozy. Mesure et démesure du discours (2007-2012). Paris : Presses de Sciences Po.

Memmi, Albert. 1982. Le racisme. Description, définition, traitement. Paris : Gallimard.

Merle, Isabelle. 2002. «Retour sur le régime d’indigénat: genèse et contradictions des principes répressifs dans l'Empire français ». French Politics, Culture \& Society 20 (2) : 77-97.

Mignon, Emmanuelle. 2007. «La machine à idées de Sarkozy. Un entretien exclusif avec Emmanuelle Mignon ». < <ttp://www.nonfiction.fr/article-443la_machine_a_idees_de_sarkozy_premiere_partie.htm> $<$ http://www.nonfiction.fr/article-444-

la_machine_a_idees_de_sarkozy_seconde_partie.htm> (consulté le 28 août 2018).

Moussa, Nedijb Sid. 2017. La fabrique du musulman. Essai sur la confessionnalisation et la racialisation de la question sociale. Paris : Libertalia. 
Muller, Pierre. 2005. «Esquisse d'une théorie du changement dans l'action publique. Structures, acteurs et cadres cognitifs ». Revue française de science politique 55 (1) : 155-187.

Noiriel, Gérard. 2007. À quoi sert l’« identité nationale ». Marseille : Agone.

Open Society Foundations. 2011. Un voile sur les Réalités. 32 musulmanes de France expliquent pourquoi elles portent le voile intégral. <https://www.opensocietyfoundations.org/sites/default/files/aa-unveiling-the-truthfrench-20110411_0.pdf> (consulté le 28 août 2018).

Ozouf, Mona. 1982. L'École, l'Église et la République. Paris : Éditions Cana/Jean Offredo.

Parvez, Z. Fareen. 2011. «Debating the Burqa in France: the Antipolitics of Islamic Revival». Qualitative Sociology 34 (2) : 287-312.

Pelletier, Denis. 2007. «La République des catholiques». Dans Dictionnaire critique de la République, dir. Vincent Duclert et Christophe Prochasson. Paris : Flammarion, 313-319.

Perrineau, Pascal et Collette Ysmal, dir. 2003. Le vote de tous les refus. Les élections présidentielle et législative 2002. Paris: Presses de Sciences Po.

Portier, Philippe. 2008a. "Retour sur la "laïcité positive" de Nicolas Sarkozy. Néocléricalisme ou ultramodernité ? ». Esprit. Revue internationale 344 : 196-198.

Portier, Philippe. 2008b. «Pluralité et unité dans le catholicisme français ». Dans Catholicisme en tensions, dir. Céline Béraud, Frédérique Guelot et Isabelle Saint-Martin. Paris : Editions de l'EHESS, 19-36.

Portier, Philippe. 2016. L'État et les religions en France. Une sociologie historique de la laïcité. Rennes : Presses Universitaires de Rennes.

Poulat, Émile. 2010. Scruter la loi de 1905. La République française et la Religion. Paris : Fayard.

Raoult, Éric, dir. 2010. Rapport fait en application de l'article 145 du Règlement au nom de la mission d'information sur la pratique $d u$ port $d u$ voile intégral sur le territoire national. <http://www.assemblee-nationale.fr/13/pdf/rap-info/i2262.pdf> (consulté le 28 août 2018).

Rosanvallon, Pierre. 1992. Le sacre du citoyen. Histoire du suffrage universel en France. Paris : Gallimard.

Rosanvallon, Pierre. 2004. Le modèle politique français. La société civile contre le jacobinisme de 1789 à nos jours. Paris : Seuil.

Sarkozy, Nicolas. 2004. La République, les religions, l'espérance. Paris : Les Éditions du Cerf.

Sarkozy, Nicolas. 2007. Discours de Latran».

<http://www.lemonde.fr/politique/article/2007/12/21/discours-du-president-de-larepublique-dans-la-salle-de-la-signature-du-palais-du-latran_992170_823448.html> (consulté le 28 août 2018). 
Sellam, Sadek. 2006. La France et ses musulmans. Un siècle de politique musulmane 1895-2005. Paris :

Fayard.

Stasi, Bernard, dir. 2003. Rapport au Président de la République (Commission de réflexion sur l'application du principe de la laïcité dans la République). $<$ http://www.ladocumentationfrancaise.fr/var/storage/rapportspublics/034000725.pdf> (consulté le 28 août 2018).

Terrel, Hervé. 2008. "L'État et la création du Conseil français du culte musulman (CFCM)».

Dans L'islam en France, dir. Cynthia Fleury, Sylvie Taussig et Yves C. Zarka. Paris : PUF, 67-92.

Union pour un mouvement populaire (UMP). 2011. Laïcité: pour mieux vivre ensemble. <http://www.lefigaro.fr/assets/pdf/laicite-0504-ump.pdf> (consulté le 28 août 2018).

Valls, Manuel. 2005. La laïcité en face. Entretiens avec Virginie Malabard. Paris : Desclée de Brouwer.

Vauchez, Stéphanie H. et Vincent Valentin. 2014. L'affaire Baby Loup ou la Nouvelle Laïcité. Paris : LGDJ.

Weil, Patrick. 2008. Liberté, égalité, discriminations. L'«identité nationale » au regard de l'bistoire. Paris : Éditions Grasset \& Fasquelle.

Zeghal, Malika. 2005. «La constitution du Conseil Français du Culte Musulman : reconnaissance politique d'un Islam français? ». Archives de sciences sociales des religions 129 : 97-113.

\footnotetext{
${ }^{1}$ Cet article reprend des analyses publiées en langue allemande (Lindner, 2017). Je remercie Philippe Bongrand, Émilien Fargues, Edwin Hatton, Igor Martinache, Sarah Perret et Bruno Quélennec ainsi que les trois rapporteur.e.s anonymes de leurs lectures et suggestions.

${ }^{2}$ Je tire cette distinction du débat sur le concept d'hégémonie qui trouve son origine chez Antonio Gramsci et qui est développé et peaufiné dans la réception ultérieure (Lindner, à paraitre). Pour comprendre comment le volet motivationnel a concrètement été travaillé par la droite sarkozyste : Confavreux et Lindgaard, 2007.

${ }^{3}$ Je tiens toutefois à signaler que ce « deuxième seuil » de laïcisation forgeant notamment l'institution républicaine par excellence, l'école publique, suit un premier seuil allant «globalement de 1789 à 1806 » (Baubérot, 2004 : 55). Ce dernier instaure des droits civiques indépendants de l'appartenance religieuse notamment par la Déclaration des droits de l'homme et du citoyen de 1789 et le Code civil de 1804.

${ }^{4}$ Cette source est toutefois ambivalente dans la mesure où l'anticléricalisme soutenant l'idée d'un espace public aseptique est historiquement ancrée dans la confrontation entre République et Église catholique qui est difficilement transposable à l'islam. Ainsi, les anticléricaux sont assez tolérants par rapport au culte musulman en Algérie coloniale (Dimier, 2001).

${ }^{5}$ Ce groupe l'emporte également lors du débat parlementaire sur le port public des signes religieux ostentatoires en dehors du service ecclésial, à savoir la soutane. Il s'agit d'une querelle qui rappelle pour beaucoup la récente polémique sur le port du voile, notamment par l'idée « que ce vêtement est un signe 'd'obéissance opposé à la dignité humaine', mais aussi 'un acte permanent de prosélytisme'» (Portier, 2016: 137, note). La soutane échappe à l'interdiction: la liberté d'expression garantit le droit de se vêtir d'un tel habit dans l'espace public. De plus, on souligne, dans le débat parlementaire, qu'il n'appartiendrait pas à l'État d'émanciper, par la loi, les prêtres d'une tenue jugée obséquieuse (Baubérot, 2006 : 179-183).

${ }^{6}$ Je laisse ici de côté l'autre biais culturel encore plus fondamental qui réside dans l'imprégnation chrétienne du modèle de sécularisation soutenant la laïcité qu'a notamment développé Talal Asad (2003).

${ }^{7}$ Une autre ironie de l'histoire de la laïcité est que l'islam algérien revendique, suite à la non-application de la loi de 1905, « la séparation et, d’une certaine façon donc, à prendre en compte une vision sécularisée de la politique et du rapport à l'État (même colonial)» (Bozzo, 2006 : 217). C'est donc la dérogation à la laïcité qui fait naittre une revendication islamique en faveur de son application. Ainsi, l'ouverture de mosquées libres devient un élément important dans la programmatique anticoloniale du mouvement de libération nationale.
} 
${ }^{8}$ Racisme désigne ici un processus trinôme qui consiste « en une mise en relief de différences; en une valorisation de ces différences ; enfin, en une utilisation de cette valorisation au profit de l'accusateur» (Memmi, 1982 : 43). Le racisme forme donc un ensemble de racisation ainsi que de dévalorisation et renvoie au pouvoir de mettre en œuvre la marginalisation et l'oppression des groupes racisés.

${ }_{9}^{9}$ Dans un long entretien, le Nicolas Sarkozy soutient que «même les musulmans qui ne pratiquent pas ont reçu l'islam comme un héritage au moins culturel. Pour un musulman croyant, comme pour un musulman non croyant, l'islam est une partie de son identité. Il a été élevé avec lui, il a grandi avec cette référence. La question de la représentation de l'islam de France est donc importante, y compris pour un musulman athée. » (2004: 60)

${ }^{10}$ Nicolas Sarkozy renouvelle ainsi une politique publique conduite notamment sous la présidence de Valéry Giscard d'Estaing. C'est dans la deuxième moitié des années 1970 qu'on favorise, au niveau de l'État et avec l'appui de l'Église catholique et des entreprises, l'ouverture des salles de prières musulmanes dans les usines et les HLM. Cette intervention vise la création d'un « islam de paix sociale » comme alternative à la délinquance ainsi qu'à l'organisation politique et syndicale (Kepel, $1987: 125-175)$.

${ }^{11}$ Les signes religieux dits ostentatoires sont au cœur du débat public au printemps 2003, après que Nicolas Sarkozy se soit fait huer lors du congrès annuel de l'UOIF en avril 2003 pour sa défense de l'interdiction du voile sur les photos d'identité. Le Ministre de l'Intérieur qui essayait, par son discours, de prouver sa fermeté, mise en doute par sa coopération avec l'UOIF dans le cadre du CFCM, déclenche ainsi un véritable «psychodrame national » (Frégosi, 2008 : 449). Celui-ci échappe complètement à la communication politique soignée que pratique la place Beauvau depuis mai 2002. Malgré un nombre d'incidents qui l'implique à la baisse, le port du voile par des jeunes filles à l'école publique monopolise l'attention médiatique par la suite : «Le journal PLPL a donné une idée du matraquage médiatique dans la seule presse écrite - il a été plus violent encore à la radio et à la télévision - en recensant les références à la question du foulard dans Le Monde, Libération et Le Figaro entre septembre 2003 et février 2004, c'est-àdire au plus fort de la crise : “Au total, 1.284 articles, enquêtes, reportages, brèves, éditoriaux, chroniques, 'Rebonds', 'Horizons', courriers des lecteurs qui ont envahi les pages des trois quotidiens nationaux. Soit en moyenne deux articles par jour dans chaque quotidien durant six mois.” Dans le même temps, le projet de réforme de la Sécurité sociale n'est apparu que 478 fois, presque trois fois moins » (Deltombe, 2005 : 344). On peut à nouveau parler d'une «panique morale».

${ }^{12}$ Il est important de noter que les collaborateurs du Ministre de l'Intérieur (Emmanuelle Mignon et Vianney Sevaistre) aussi bien que Nicolas Sarkozy lui-même s'opposent vivement dans leurs auditions respectives à l’idée d'une telle laïcité restrictive. François Baroin, à son tour, fait partie de la commission parlementaire.

13 Je dois cette indication à Philippe Portier.

${ }^{14}$ Une décision du 27 juin 2008 traduisant le " "raidissement jurisprudentiel" du Conseil d'État dans sa régulation du religieux » (Koussens, 2015 : 182) constitue le point de départ de cette campagne : une ressortissante marocaine se voit refusée la nationalité française parce que sa pratique religieuse est estimée comme radicale et incompatible avec les valeurs essentielles de la communauté française, en particulier l'égalité des sexes. Bien que le Conseil d'État ne mentionne pas le vêtement religieux de la requérante, la presse en parle rapidement, faisant de la décision «l'affaire de la burqa ». Maryam Borghée soutient que l'emploi du terme de burqa témoigne d'un biais du débat: "Dans nos esprits, la burqa constitue l'emblème du régime des talibans et un outil d'oppression des islamistes à l'encontre des femmes. La burqa et le tchadri sont des vêtements traditionnels antiques, portés en Afghanistan et au Pakistan; souvent bleus, gris ou organe, ils appartiennent à un espace culturel et géographique délimité. Le voile intégral porté en France ne peut en aucun cas être assimilé à la burqa, car il n'existe pas d'isomorphie systémique entre un fait social français et un fait social oriental: les réalités historiques, politiques, sociologiques et psychologiques sont radicalement différentes. Les Françaises, elles, choisissent et revendiquent leur voile intégral dans un contexte laïc et sécularisé, démocratique et postmoderne » (Borghée, 2012 : 32 passim).

${ }^{15}$ Sur le plan individuel, le port du voile intégral est perçu comme une «affirmation radicale de personnalités en quête d'identité dans l'espace social» (Raoult, 2010 : 41) marqué par la précarité. Cependant, les études scientifiques du phénomène dont nous disposons ne confirment pas l'idée, soutenue par la mission d'information, d'une pratique revendiquante qui est surtout due à des pressions religieuses ou familiales. Au contraire, le voile intégral semble plutôt traduire une démarche «antipolitique »: « une reconfiguration de la sphère privée contre un État intrusif, un retrait dans une communauté morale et l'accentuation des conditions spirituelles ainsi que l'accomplissement de la sérénité » (Parvez, 2011 : 287). Une autre recherche montre que «l'adoption du voile intégral est dans la grande majorité des cas le résultat d'un choix personnel, sans que la moindre pression ait été exercée par des membres de la famille»(Open Society Foundations, 2011 : 15). Il en ressort aussi que «l'adoption du voile intégral n'est pas synonyme de refus de socialisation », mais qu'au contraire, "dans la majorité des cas, les femmes interrogées ont une vie sociale active» (ibid. : 13). Les conclusions sont aussi contrastées en ce qui concerne la subjectivation résultant de cette pratique vestimentaire. Contrairement à l'institution parlementaire qui évoque une "affirmation d'une identité construite par pure opposition à la société française» (Raoult, 2010 : 54) et un "synonyme de rejet, de négation, d'exclusion, de repli, de fermeture, de refus de l'autre» (ibid. : 122), la sociologue Maryam Borghée avance que le comportement en question « concerne principalement un sujet anomique qui ne parvient pas à se construire selon les voies habituelles» (2012: 39 passim). Le voile intégral serait «un emblème de soi» (ibid. : 79), un «marqueur vestimentaire» (ibid. : 84) d'une «lutte pour la reconnaissance» (ibid.) qui «ne doit justement pas être compris comme une volonté d'annihilation » (ibid. : 112). 
${ }^{16}$ Un fait divers va renforcer le caractère national du débat après la présentation des résultats du travail de la mission. En avril 2010, la police nantaise verbalise une femme convertie à l'islam intégralement voilée et conduisant une voiture. Par la suite, le Ministre de l'Intérieur, Brice Hortefeux, se fera remarquer en soumettant l'idée hautement controversée de déchoir de sa nationalité son mari algérien naturalisé français.

${ }^{17}$ Cette comparaison lui vaut un procès pour incitation à la haine raciale au bout duquel elle est relaxée en décembre 2015.

${ }^{18}$ Charlotte Denizeau (2014 : 120-125) rappelle par ailleurs les dispositions prévues par la loi de 1905 concernant les lieux de l'exercice du culte. Bien que personne n'ait évoqué les articles en question (28 et 35) dans le débat public en 2010/11, il s'agit en fait des seuls éléments de la loi qui pourraient soutenir une interdiction de la pratique religieuse en question. Une réaction accommodante et respectueuse de la liberté de conscience semble cependant davantage correspondre à l'esprit du texte dont j'ai fait ressortir qu'il ne soutient pas de rigueur « laïcarde ». 